\title{
ESTOQUES DE CARBONO E NITROGÊNIO E FRAÇÕES ORGÂNICAS DE LATOSSOLO SUBMETIDO A DIFERENTES SISTEMAS DE USO E MANEJO(1)
}

\author{
Otacílio José Passos Rangel ${ }^{(2)} \&$ Carlos Alberto Silva ${ }^{(3)}$
}

\begin{abstract}
RESUMO
O avanço das fronteiras agrícolas, caracterizado pela substituição de ecossistemas naturais por áreas cultivadas, vem se intensificando nas últimas décadas, acarretando alterações na qualidade do solo e na dinâmica da matéria orgânica do solo (MOS). Assim, o estudo do impacto da adoção de diferentes sistemas de manejo é essencial na definição de melhores estratégias de uso do solo. Este estudo teve por objetivo avaliar diferentes frações da MOS e os estoques de C e $\mathbf{N}$ de Latossolo Vermelho distroférrico típico muito argiloso submetido a diferentes sistemas de uso e manejo: mata nativa (MTN), eucalipto (EUC), pinus (PIN), pastagem (PAS), milho no sistema de cultivo mínimo (MCM) e milho no sistema plantio convencional (MPC). As amostras de solo foram coletadas em setembro de 2004, nas profundidades de 0-10, 10-20 e 20-40 cm, para avaliação dos estoques de carbono orgânico (CO) e $N$ total (NT); de 0-5 e 0-10 cm, para realização do fracionamento físico-densimétrico da MO; e de 0-5 cm, para avaliação do C da biomassa microbiana (Cmic). O estoque de CO na área de eucalipto foi maior do que o determinado na área de mata. A proporção relativa do CO nas frações da MOS aumentou na seguinte ordem: $\mathrm{C}$-argila $>\mathrm{C}$-silte $>\mathrm{C}$-areia $>\mathrm{C}_{\mathrm{FL}}$. A maior parte (> $90 \%$ ) do CO está associada à fração pesada da MOS, com valores próximos a $98 \%$ nos sistemas cultivados com milho (MPC e MCM). Em relação aos teores de CO, o $C_{\text {mic }}$ e o $C$ da fração leve $\left(C_{F L}\right)$ são indicadores mais sensíveis das alterações decorrentes da adoção de diferentes sistemas de uso e manejo sobre os compartimentos da matéria orgânica do Latossolo.
\end{abstract}

Termos de indexação: fracionamento físico-densimétrico, biomassa microbiana, mudanças climáticas globais, uso do solo, mudanças no uso do solo e reflorestamento.

\footnotetext{
(1) Parte da Tese de Doutorado do primeiro autor desenvolvida no Departamento de Ciência do Solo da Universidade Federal de Lavras - UFLA. Recebido para publicação em março de 2006 e aprovado em agosto de 2007.

${ }^{(2)}$ Doutor em Solos e Nutrição de Plantas, Departamento de Ciência do Solo, Universidade Federal de Lavras - UFLA. Caixa Postal 3037, CEP 37200-000 Lavras (MG). E-mail: otaciliorangel@yahoo.com.br

(3) Professor Adjunto do Departamento de Ciência do Solo, UFLA. E-mail: csilva@ufla.br
} 


\title{
SUMMARY: CARBON AND NITROGEN STORAGE AND ORGANIC FRACTIONS IN LATOSOL SUBMITTED TO DIFFERENT USE AND MANAGEMENT SYSTEMS
}

\begin{abstract}
The advance of the agricultural frontier, characterized by the conversion of natural ecosystems into cultivated areas, was intensified in the last decades. Most of the practices used to manage soils cause changes in the soil quality and soil organic matter (SOM) dynamics. Studying the impact of different management systems is essential to choose the most adequate soil management practices. This study aimed to evaluate different SOM fractions and carbon and nitrogen storage of a very clayey typic dystroferric Red Latosol (Oxisol) under the following use and management systems: native forest (MTN), eucalyptus (EUC), pine (PIN), pasture (PAS), corn under minimum tillage (MCM) and corn under conventional till (MPC). The soil samples were collected in September 2004, in the 0-10, 10-20 and 20-40 cm layers to assess organic carbon $(O C)$ and total nitrogen (TN) storage, in the $0-5$ and $0-10 \mathrm{~cm}$ layers for the physical-densimetric SOM fractionation, and at $0-5 \mathrm{~cm}$ to measure the carbon content of the microbial biomass (Cmic). OC storage in the EUC soil was higher than in the MTN soil. The relative contribution of $C$ increased in the order: $C$-clay $>C$-silt $>C$-sand $>C_{L F}$. The largest proportion ( $>90 \%$ of $O C$ was associated to the heavy fraction of SOM, with values close to $98 \%$ in the tillage systems with corn (MPC and MCM). The Cmic and $C$-light fraction $\left(C_{L F}\right)$ were more sensitive to evaluate changes in SOM dynamics caused by the different use and management systems of the studied Latosol.
\end{abstract}

Index terms: densimetric fractionation, microbial biomass, global climate change, land use, land-use change and forestry (LULUCF).

\section{INTRODUÇÃO}

A conversão de ecossistemas naturais em sistemas agrícolas envolve uma série de atividades que afetam as taxas de adição e decomposição da matéria orgânica do solo (MOS) (Zinn et al., 2005). Em sistemas naturais, os fatores de formação do solo são os determinantes primários dos processos de ciclagem de $\mathrm{C}$, uma vez que exercem influência sobre o aporte de resíduos e sobre as saídas de $\mathrm{C}$ do solo (Stevenson, 1994). Em sistemas agrícolas, o uso e o manejo do solo atuam modificando tanto a entrada como a saída de $\mathrm{C}$ do solo para a atmosfera, em função da produção diferenciada de resíduos, do número de cultivos, das espécies vegetais, da adubação, dos procedimentos de colheita, dos métodos adotados de preparo do solo e do manejo dos restos culturais (Lal \& Bruce, 1999).

Em ecossistemas naturais, quando a vegetação nativa é substituída por sistemas agrícolas, os estoques de carbono orgânico (CO) podem ser drasticamente reduzidos, com perdas da ordem de $50 \%$ nos primeiros $20 \mathrm{~cm}$ de profundidade do solo e de até $20 \%$ na profundidade de um metro (Estados Unidos, 1999). Em regiões tropicais, as condições de temperaturas elevadas, os altos índices pluviométricos e, em conseqüência, a intensa atividade microbiana propiciam a rápida decomposição dos materiais orgânicos depositados no solo (Silva \& Machado, 2000; Mielniczuk et al., 2003). Segundo Zinn et al. (2005), as maiores taxas de decomposição da MOS observadas em áreas sob cultivo ocorrem devido às perturbações físicas do solo, que implicam rompimento dos macroagregados (reduz a proteção física da MOS), expondo a MO protegida aos processos microbianos, contribuindo, dessa forma, para aumentar as taxas de emissão de $\mathrm{CO}_{2}$ para a atmosfera. Essas perdas de MO em áreas cultivadas adquirem importância, em razão de dois aspectos principais: (a) anualmente, cerca de 1,2 Pg C $\left(\right.$ Pg, Petagrama $=10^{15}$ gramas) são lançados na atmosfera devido a alterações nos sistemas de uso e manejo dos solos agrícolas (Suaerbeck, 2001); e (b) o solo é um dos compartimentos que mais armazenam $\mathrm{C}$ na Terra, de modo que, em termos globais, o primeiro metro superior do solo armazena 2,5 vezes mais $\mathrm{C}$ que a vegetação terrestre e duas vezes mais $\mathrm{C}$ que o presente na atmosfera (Lal, 2002). O estoque de CO no primeiro metro de solo é estimado entre $1.462 \mathrm{e}$ $1.548 \mathrm{Pg}$, enquanto na profundidade de até dois metros ele varia de 2.376 a 2.456 Pg (Batjes, 1999). Desse modo, em virtude das quantidades de $\mathrm{C}$ que armazena, o solo é um dos condicionantes de processos poluentes do ar, tendo em vista que a variação no estoque de $\mathrm{C}$ regula os teores desse elemento emitidos para a atmosfera.

Os estoques de $\mathrm{N}$ do solo são controlados especialmente pelas condições climáticas e pela vegetação. Em solos sob clima tropical, a concentração de $\mathrm{N}$ total pode 
variar entre 0,02 e $0,4 \%$, podendo, em casos extremos de solos orgânicos, chegar a até $2 \%$ (Stevenson, 1994). A maior parte do $\mathrm{N}$ do solo se encontra na forma orgânica (mais de 95 \%), sendo a MOS um importante reservatório de formas potencialmente disponíveis de $\mathrm{N}$ para os vegetais, principalmente o $\mathrm{N}$ nítrico $\left(\mathrm{N}-\mathrm{NO}_{3}{ }^{-}\right)$e o amoniacal $\left(\mathrm{N}-\mathrm{NH}_{4}{ }^{+}\right)$. A mineralização da MOS, que engloba os processos de aminação e amonificação, é responsável, por ano, pela conversão de 2 a $5 \%$ do $\mathrm{N}$ orgânico em $\mathrm{N}$ mineral. Esse processo é regulado pelo uso e manejo do solo (Moreira \& Siqueira, 2002; D’Andréa et al., 2004), notadamente pelas espécies que são incluídas nos esquemas de rotação de culturas, de modo que o maior uso de leguminosas e a implantação de espécies com maior produção de biomassa causam maior armazenamento de $\mathrm{N}$ total no solo (Mielniczuk et al., 2003).

Dentre os atributos biológicos sensíveis às alterações nos sistemas de manejo do solo e culturas, destaca-se a biomassa microbiana, que representa a parte viva da MOS e contém, em média, de 2 a $5 \%$ do $\mathrm{CO}$ e até $5 \%$ do $\mathrm{N}$ total nos solos tropicais (Smith \& Paul, 1990). O C da biomassa microbiana, por ser o destino inicial do $\mathrm{C}$ em transformação no solo, apresenta rápida ciclagem, responde intensamente a flutuações sazonais de umidade e temperatura e ao manejo dos resíduos e é o compartimento da MOS que responde mais rapidamente às mudanças nos sistemas de manejo, podendo ser utilizado, em relação ao teor de $\mathrm{CO}$, como identificador mais precoce de alterações na MOS e na qualidade do solo (Powlson et al.,1987; Anderson \& Domsch, 1989).

Os diversos tipos de fracionamento utilizados em estudos de MOS procuram separar frações homogêneas quanto à natureza, dinâmica e função, mas, ao mesmo tempo, suficientemente diferentes uma das outras (Christensen, 2000). O fracionamento físico-densimétrico da MOS é um ferramenta importante nos estudos que envolvem mudanças nos sistemas de uso e manejo do solo (Christensen, 2000), sendo um procedimento mais sensível, em relação ao fracionamento químico, em verificar alterações em frações da MOS decorrentes da adoção de diferentes sistemas de manejo do solo (Golchin et al., 1997; Roscoe \& Buurman, 2003). Outra característica importante dos métodos de fracionamento físico é sua natureza menos destrutiva e mais relacionada com a função e estrutura da MOS in situ (Christensen, 2000; Roscoe \& Machado, 2002).

$\mathrm{O}$ uso do fracionamento físico-densimétrico nos estudos da MOS possibilita a separação de diferentes compartimentos orgânicos, cada qual respondendo, de forma distinta, às diferentes práticas de uso e manejo do solo (Collins et al., 1997; Freixo et al., 2002). Em regiões temperadas, esse procedimento tem sido usado com maior freqüência nos estudos que avaliam os compartimentos e a biodisponibilidade da MOS, sendo, desse modo, premente o uso dessa ferramenta nas condições de solos brasileiros, já que a MO desempenha aqui papel mais importante do que o exercido em solos de regiões mais frias.
Este estudo teve por objetivo avaliar as diferentes frações da $\mathrm{MO}$ e os estoques de $\mathrm{C}$ e $\mathrm{N}$ de Latossolo Vermelho distroférrico típico submetido a diferentes sistemas de uso e manejo.

\section{MATERIAL E MÉTODOS}

\section{Características do solo e sistemas de manejo em estudo}

O estudo foi realizado utilizando-se amostras de Latossolo Vermelho distroférrico típico textura muito argilosa, localizado no campus da Universidade Federal de Lavras (21 ${ }^{\circ} 13^{\prime} 44^{\prime \prime} \mathrm{S}, 44^{\circ} 57^{\prime} 50$ " W e $925 \mathrm{~m}$ de altitude), em Lavras (MG). O clima da região foi classificado com CWa, no sistema Köppen, com inverno seco e médias anuais de precipitação e temperatura de, respectivamente, $1.530 \mathrm{~mm}$ e $19,4^{\circ} \mathrm{C}$.

$\mathrm{Na}$ avaliação dos diferentes sistemas de uso e manejo do solo, foram selecionadas seis áreas adjacentes (uma para cada tipo de uso e manejo), distribuídas numa faixa homogênea de solo. Os tipos de uso e manejo do solo avaliados foram: mata nativa, eucalipto, pinus, pastagem, milho no sistema de cultivo mínimo e milho em sistema plantio convencional. A escolha desses sistemas de uso e manejo foi feita com base no histórico de uso e nas características dos sistemas de manejo adotados. As principais características dos sistemas avaliados são apresentadas no quadro 1 . As características químicas e texturais do solo nos seis sistemas, efetuada com base em amostras coletadas nas profundidades de 0-20 e 20-40 cm, são apresentadas no quadro 2. $\mathrm{O}$ método utilizado para avaliação dos atributos químicos está descrito em Silva (1999), enquanto a análise granulométrica foi efetuada pelo método da pipeta (Day, 1965), após dispersão da amostra com $\mathrm{NaOH} 1 \mathrm{~mol} \mathrm{~L}^{-1}$ e agitação rápida (6.000 rpm) por $15 \mathrm{~min}$.

\section{Amostragem do solo}

As amostragens de solo foram efetuadas em setembro de 2004, selecionando-se em cada sistema três blocos retangulares com dimensões individuais de 15 x $20 \mathrm{~m}\left(300 \mathrm{~m}^{2}\right)$. Foram retiradas amostras nas profundidades de 0-10, 10-20 e 20-40 cm, para avaliação dos estoques de CO e NT; nas profundidades de 0-5 e 0-10 cm, para realização do fracionamento físico-densimétrico da MO; e na profundidade de 0 $5 \mathrm{~cm}$, para avaliação do $\mathrm{C}$ da biomassa microbiana do solo $\left(\mathrm{C}_{\text {mic }}\right)$. Para cada bloco e profundidade, em determinado sistema de uso e manejo, foram retiradas três amostras compostas, oriundas de 10 subamostras coletadas ao acaso, cada uma constituindo uma repetição. Para avaliação da densidade do solo, coletaram-se três amostras indeformadas em cada sistema e profundidade (0-10, 10-20 e 20-40 cm), com auxílio de um anel volumétrico de $100 \mathrm{~cm}^{3}$. Nas áreas 


\section{Quadro 1. Características dos sistemas de uso e manejo instalados em Latossolo Vermelho distroférrico típico, no município de Lavras (MG)}

\begin{tabular}{|c|c|c|}
\hline Sistema de uso e manejo & Símbolo & Histórico \\
\hline Mata nativa & MTN & $\begin{array}{l}\text { Remanescente de mata nativa do tipo floresta estacional semidecídua } \\
\text { montada (Oliveira Filho et al., 1994), sem qualquer exploração ou } \\
\text { interferência antrópica. }\end{array}$ \\
\hline Eucalipto & EUC & $\begin{array}{l}\text { Área anteriormente cultivada com cafeeiro, onde, no ano de } 1975 \text {, foi } \\
\text { instalado um estudo de Teste de Procedência com diversas espécies de } \\
\text { Eucaliptus oriundas da Austrália e Indonésia. O plantio foi realizado } \\
\text { no espaçamento } 3 \times 2 \mathrm{~m} \text {, com adubação de plantio recomendada para } \\
\text { a cultura e preparo convencional do solo (aração+gradagem). Não foi } \\
\text { realizado nenhum corte de árvores. }\end{array}$ \\
\hline Pinus & PIN & $\begin{array}{l}\text { Povoamento de Pinus sp. implantado em 1975, em área antes } \\
\text { cultivada com cafeeiro, utilizando o espaçamento } 3 \text { x } 3 \mathrm{~m} \text {. Efetuou-se } \\
\text { o preparo convencional do solo (aração+gradagem) para o plantio e } \\
\text { realizaram-se as adubações recomendadas para a cultura. Não foi } \\
\text { realizado nenhum corte de árvores. }\end{array}$ \\
\hline Pastagem & PAS & $\begin{array}{l}\text { Pastagem de Brachiaria decumbens implantada em } 1992 \text {, conduzida } \\
\text { sob pastejo contínuo de bovinos em regime semi-intensivo e sem } \\
\text { manejo da fertilidade do solo. }\end{array}$ \\
\hline $\begin{array}{l}\text { Milho: sistema de cultivo } \\
\text { mínimo }\end{array}$ & $\mathrm{MCM}$ & $\begin{array}{l}\text { Sistema de cultivo mínimo sem revolvimento do solo implantado } \\
\text { desde o ano agrícola de } 1993 / 1994 \text {, com cultivo principal de milho no } \\
\text { verão sucedido por feijão no inverno. O controle das plantas daninhas } \\
\text { foi feito com herbicidas pré e pós-emergentes para o milho e pós- } \\
\text { emergente para o feijão. A adubação e calagem das culturas seguiram } \\
\text { as recomendações descritas em CFSEMG (1989). }\end{array}$ \\
\hline $\begin{array}{l}\text { Milho: sistema plantio } \\
\text { convencional }\end{array}$ & MPC & $\begin{array}{l}\text { Sistema plantio convencional recente ( } 4 \text { anos), com o preparo do solo } \\
\text { realizado com uma aração e duas gradagens. O controle das plantas } \\
\text { daninhas neste sistema foi feito com a aplicação de herbicidas pré- } \\
\text { emergentes. Não houve plantio de feijão ou qualquer outra } \\
\text { leguminosa em sucessão ao milho. A adubação e a calagem da cultura } \\
\text { foram feitas de acordo com CFSEMG (1989). }\end{array}$ \\
\hline
\end{tabular}

de milho, a amostragem do solo foi realizada após colheita dos grãos. Em todos os sistemas de uso e manejo, antes da coleta das amostras de solo, foram removidos os resíduos vegetais presentes na superfície do solo.

As amostras compostas foram acondicionadas em sacos plásticos e conduzidas para o laboratório. $\mathrm{Na}$ análise dos teores de CO e NT, necessária para cálculo dos estoques desses elementos em solo, as amostras foram secas ao ar, destorroadas, trituradas em almofariz e passadas em peneira de malha de $0,210 \mathrm{~mm}$. As amostras para realização do fracionamento físico-densimétrico foram secas ao ar, destorroadas e passadas em peneira de $2 \mathrm{~mm}$ (terra fina seca ao ar-TFSA). As amostras coletadas no campo para análise do $\mathrm{C}_{\mathrm{mic}}$ foram acondicionadas em sacos plásticos, protegidas da luz e mantidas em caixas térmicas. No laboratório, essas amostras foram passadas em peneiras de malha de $4 \mathrm{~mm}$, acondicionadas em sacos plásticos com respirador e mantidas em câmara fria $\mathrm{a} \pm 4{ }^{\circ} \mathrm{C}$, até realização da análise de $\mathrm{C}_{\text {mic }}$.

\section{Análises químicas e microbiológicas Carbono orgânico do solo}

O CO do solo foi determinado pelo método descrito em Yeomans \& Bremner (1988), após digestão de 0,3 g de solo em $5 \mathrm{~mL}$ de $\mathrm{K}_{2} \mathrm{Cr}_{2} \mathrm{O}_{7}$ 0,167 $\mathrm{mol} \mathrm{L}^{-1}$ e $10 \mathrm{~mL}$ de $\mathrm{H}_{2} \mathrm{SO}_{4}$ p.a., por $30 \mathrm{~min}$ a $170{ }^{\circ} \mathrm{C}$, em bloco digestor de 40 provas. Após resfriamento em temperatura ambiente, os extratos foram transferidos quantitativamente para frascos erlenmeyers de $125 \mathrm{~mL}$, utilizando-se água destilada suficiente para obter volume final de 
Quadro 2. Caracterização química e textura de Latossolo Vermelho distroférrico típico submetido a diferentes sistemas de uso e manejo (valores médios de três repetições)

\begin{tabular}{|c|c|c|c|c|c|c|c|c|c|}
\hline \multirow{2}{*}{ Sistema de uso e manejo } & \multicolumn{6}{|c|}{ Atributo químico } & \multicolumn{3}{|c|}{ Granulometria } \\
\hline & $\begin{array}{c}\mathrm{pH} \\
\mathrm{H}_{2} \mathrm{O}\end{array}$ & $\mathrm{Ca}^{2+}$ & $\mathrm{Mg}^{2+}$ & $\mathrm{Al}^{3+}$ & \multicolumn{2}{|c|}{ (Mehlich-1) } & Areia & Silte & Argila \\
\hline & & \multicolumn{3}{|c|}{$\mathrm{cmol}_{\mathrm{c}} \mathrm{kg}^{-1}$} & $\begin{array}{c}-\mathrm{m} \\
0-20\end{array}$ & 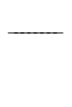 & \multicolumn{2}{|c|}{$\mathrm{g} \mathrm{kg}^{-1}$} & 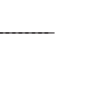 \\
\hline MTN & 4,4 & 0,7 & 0,2 & 1,8 & 1,0 & 30 & 120 & 170 & 710 \\
\hline EUC & 4,5 & 0,6 & 0,2 & 1,9 & 1,5 & 21 & 180 & 70 & 750 \\
\hline PIN & 4,6 & 0,5 & 0,2 & 1,3 & 1,6 & 11 & 240 & 40 & 720 \\
\hline PAS & 5,8 & 2,7 & 0,4 & 0,2 & 1,8 & 74 & 180 & 140 & 680 \\
\hline $\mathrm{MCM}$ & 6,1 & 3,2 & 1,0 & 0,0 & 35,6 & 75 & 140 & 120 & 740 \\
\hline \multirow[t]{2}{*}{ MPC } & 5,6 & 2,2 & 0,3 & 0,2 & 25,3 & 116 & 140 & 170 & 690 \\
\hline & \multicolumn{9}{|c|}{$20-40 \mathrm{~cm}$} \\
\hline MTN & 4,5 & 0,6 & 0,2 & 1,2 & 0,6 & 19 & 130 & 90 & 780 \\
\hline EUC & 4,7 & 0,5 & 0,2 & 1,8 & 1,1 & 20 & 170 & 80 & 750 \\
\hline PIN & 4,7 & 0,5 & 0,2 & 1,0 & 1,0 & 8 & 230 & 50 & 720 \\
\hline PAS & 5,6 & 1,5 & 0,5 & 0,2 & 0,5 & 50 & 170 & 60 & 770 \\
\hline $\mathrm{MCM}$ & 5,8 & 2,0 & 0,7 & 0,0 & 4,5 & 42 & 130 & 90 & 780 \\
\hline MPC & 5,5 & 2,0 & 0,3 & 0,2 & 6,5 & 63 & 130 & 110 & 760 \\
\hline
\end{tabular}

MTN: mata nativa; EUC: eucalipto; PIN: pinus; PAS: pastagem; MCM: milho cultivado no sistema de cultivo mínimo; MPC: milho cultivado no sistema plantio convencional.

aproximadamente $75 \mathrm{~mL}$. Em seguida, a cada erlenmeyer foram adicionados $5 \mathrm{~mL}$ de $\mathrm{H}_{3} \mathrm{PO}_{4}$ p.a., procedendo-se à titulação com solução de $\mathrm{Fe}\left(\mathrm{NH}_{4}\right)_{2}\left(\mathrm{SO}_{4}\right)_{2} \cdot 6 \mathrm{H}_{2} \mathrm{O} 0,4 \mathrm{~mol} \mathrm{~L}^{-1}$ (sal de Mohr), sendo utilizada como indicador a solução ácida de difenilamina $1 \%$. Paralelamente, foram realizadas provas em branco, com e sem aquecimento.

\section{Nitrogênio total do solo}

Nesta determinação foi utilizado o método descrito em Bremner (1996), que envolve o uso de uma mistura digestora à base de $\mathrm{K}_{2} \mathrm{SO}_{4}, \mathrm{CuSO}_{4}$ e selênio. A cada amostra de $0,1 \mathrm{~g}$ de solo foi adicionado $1,1 \mathrm{~g}$ da mistura digestora e 3,0 $\mathrm{mL}$ de $\mathrm{H}_{2} \mathrm{SO}_{4}$ p.a. A digestão foi feita a $350{ }^{\circ} \mathrm{C}$ em bloco digestor de 40 provas, com posterior destilação a vapor. O destilado foi recolhido em solução de $\mathrm{H}_{3} \mathrm{BO}_{3}\left(20 \mathrm{~g} \mathrm{~L}^{-1}\right)$, misturada a uma solução de verde de bromocresol e vermelho de metila, e, posteriormente, titulado com solução de $\mathrm{HCl}$ $0,01 \mathrm{~mol} \mathrm{~L}^{-1}$.

Os estoques de CO e NT, nos diferentes sistemas sob estudo e em cada profundidade do solo, foram calculados pela seguinte fórmula: estoque de $\mathrm{CO}$ ou $\mathrm{NT}\left(\mathrm{t} \mathrm{ha}^{-1}\right)=$ teor de CO ou NT $\left(\mathrm{g} \mathrm{kg}^{-1}\right)$ x Ds x E/10, em que Ds = densidade do solo na profundidade $\left(\mathrm{kg} \mathrm{dm}^{-3}\right)$ (média de três repetições) e; $\mathrm{E}=$ espessura da camada de solo $(\mathrm{cm})$. Para verificar o acúmulo ou a perda de $\mathrm{CO}$, foi calculada a variação do estoque de CO em relação ao sistema referência (MTN) $\left(\Delta \mathrm{EstC}, \mathrm{t} \mathrm{ha}^{-1} \mathrm{~cm}^{-1}\right)$, pela diferença entre os valores médios de estoque de $\mathrm{CO}$ neste sistema e em cada um dos demais, dividida pela espessura $(\mathrm{cm})$ da camada de solo avaliada.

\section{Fracionamento físico-densimétrico da matéria orgânica do solo}

As frações leve e pesada da MO foram obtidas seguindo-se as recomendações descritas em Sohi et al. (2001) e Machado (2002). A separação da fração leve (FL) foi realizada com base em três repetições analíticas por amostra de solo coletada no campo. Em frascos de centrífuga de $50 \mathrm{~mL}$, foram adicionados $5 \mathrm{~g}$ de TFSA e $35 \mathrm{~mL}$ da solução de iodeto de sódio (NaI), com densidade de $1,8 \pm 0,1 \mathrm{~kg} \mathrm{~L}^{-1}$ (aferida com hidrômetro). Os frascos com a mistura foram agitados manualmente por 30 segundos, visando dispersar os agregados instáveis e permitir a flotação da fração leve (FL) na solução de $\mathrm{NaI}$, sendo, a seguir, centrifugados a $8.000 \mathrm{x} \mathrm{g}$, por $30 \mathrm{~min}$. Após a centrifugação, a FL presente na superfície da solução de $\mathrm{NaI}$ foi aspirada e filtrada em sistema com vácuo (Sistema Asséptico Sterifil, $47 \mathrm{~mm}$ Millipore), utilizando-se nesta etapa filtro de fibra de vidro de $47 \mathrm{~mm}$ de diâmetro e $2 \mu \mathrm{m}$ de retenção. A FL retida 
nos filtros foi cuidadosamente lavada com água destilada, visando remover o excesso de NaI, sendo, a seguir, levada à estufa de circulação forçada de ar para secar a $65^{\circ} \mathrm{C}$ durante $72 \mathrm{~h}$. Para determinação do teor de $\mathrm{C}$ na fração leve $\left(\mathrm{C}_{\mathrm{FL}}\right)$, foram pesados o filtro mais o resíduo orgânico separado. A seguir, a fração leve foi macerada em almofariz e passada em peneira de malha de $0,210 \mathrm{~mm}$.

Após aspiração da FL, procedeu-se à remoção do excesso de $\mathrm{NaI}$ presente no solo remanescente no frasco de centrífuga. Esse procedimento foi realizado com água destilada suficiente para igualar o peso dos frascos para centrifugação a 8.000 x g durante três minutos, sendo repetido por três vezes consecutivas.

Para separação do C associado às diferentes frações granulométricas do solo (fração pesada-FP), as três repetições analíticas foram quantitativamente transferidas para frasco com capacidade de $350 \mathrm{~mL}$ (Nalgene), utilizando-se água destilada suficiente para obter volume final de $250 \mathrm{~mL}$. A separação da fração pesada foi feita seguindo-se o método descrito em Gavinelli et al. (1995). A cada frasco de $350 \mathrm{~mL}$ com o solo das três repetições analíticas ( $\pm 15 \mathrm{~g}$ de solo) foi adicionado $0,5 \mathrm{~g}$ de hexametafosfato de sódio $\left(\mathrm{NaPO}_{3}\right)_{\mathrm{n}}$, sendo a mistura agitada por aproximadamente $14 \mathrm{~h}$ a $250 \mathrm{rpm}$. A separação da fração areia $(>53 \mu \mathrm{m})$ foi realizada por peneiramento úmido, e a das frações silte $(2-53 \mu \mathrm{m})$ e argila $(0-2 \mu \mathrm{m})$, a partir da coleta de alíquotas das frações granulométricas de 0-53 $\mu \mathrm{m}$ (argila + silte) e 0-2 $\mu$ m (argila), que foram separadas por sedimentação. Após coletadas, as frações foram secas em estufa de circulação forçada de ar a $65^{\circ} \mathrm{C}$, pesadas, maceradas em almofariz e passadas em peneira com malha de $0,210 \mathrm{~mm}$, para posterior determinação do teor de CO em cada uma das frações.

A determinação do CO nas frações leve e pesada (C-areia, C-argila + silte e C-argila) foi realizada de acordo com o método descrito em Yeomans \& Bremner (1988). O teor de CO na fração silte (C-silte) foi obtido indiretamente, pela diferença dos teores de CO nas frações argila + silte e argila.

\section{Carbono da biomassa microbiana}

O carbono da biomassa microbiana $\left(\mathrm{C}_{\text {mic }}\right)$ foi avaliado pelo método da fumigação-extração (Vance et al., 1987), sendo determinado após o ataque das amostras com clorofórmio por $24 \mathrm{~h}$, que provoca a morte dos microrganismos e liberação dos componentes celulares. A extração do $\mathrm{C}$ das amostras fumigadas e não-fumigadas foi feita com $\mathrm{K}_{2} \mathrm{SO}_{4}$ $0,5 \mathrm{~mol} \mathrm{~L}{ }^{-1}$. A $8 \mathrm{~mL}$ do extrato obtido, acondicionado em frasco erlenmeyer de $125 \mathrm{~mL}$, foram adicionados $2 \mathrm{~mL}$ de $\mathrm{K}_{2} \mathrm{Cr}_{2} \mathrm{O}_{7} 0,067 \mathrm{~mol} \mathrm{~L}^{-1}$ e $15 \mathrm{~mL}$ da solução de $\mathrm{H}_{2} \mathrm{SO}_{4} / \mathrm{H}_{3} \mathrm{PO}_{4}$, v/v: 2:1, que foram aquecidos em chapa aquecedora a $170{ }^{\circ} \mathrm{C}$ por cinco minutos. Após resfriamento em temperatura ambiente, adicionaramse $10 \mathrm{~mL}$ de água destilada e procedeu-se à titulação com solução de $\mathrm{Fe}\left(\mathrm{NH}_{4}\right)_{2}\left(\mathrm{SO}_{4}\right)_{2} \cdot 6 \mathrm{H}_{2} \mathrm{O} 0,033 \mathrm{~mol} \mathrm{~L}-1$ (sal de Mohr), utilizando-se com o indicador a difenilamina a $10 \mathrm{~g} \mathrm{~L}^{-1}$. O C presente na biomassa microbiana foi calculado pela seguinte expressão: $\mathrm{C}_{\text {mic }}=(\mathrm{CF}-\mathrm{CNF}) / \mathrm{Kec}$, em que: Cmic: $\mathrm{C}$ da biomassa microbiana ( $\mathrm{mg} \mathrm{kg}^{-1}$ de solo seco); $\mathrm{CF}$ : C oxidável da amostra fumigada; CNF: C oxidável da amostra não fumigada; e Kec: fator de conversão do C extraído do solo a $\mathrm{C}_{\text {mic. }}$ Os valores de $\mathrm{Kec}$ citados na literatura são muito variáveis, não havendo consenso a respeito do valor a ser utilizado. Com base no clima e no tipo de solo, foi utilizado neste estudo o $\mathrm{Kec}=0,26$, sugerido por Feigl et al. (1995). As determinações de $\mathrm{C}_{\text {mic }}$ foram realizadas com base em três repetições analíticas (três fumigadas e três não-fumigadas) por amostra de solo coletada no campo.

Com base nos resultados dos teores de $\mathrm{CO}$ e $\mathrm{C}_{\text {mic, }}$ foi calculada a relação $\mathrm{C}_{\text {mic/ }} \mathrm{CO}$, ou quociente microbiano, expressa em percentagem, utilizando-se a seguinte fórmula: $\left(\mathrm{C}_{\text {mic }} \mathrm{CO}\right) \times 100$.

\section{Análise estatística}

Os dados dos estoques de CO e NT e das frações de $\mathrm{C}$ foram submetidos à análise de variância, para verificação, em cada profundidade, dos efeitos dos sistemas de uso e manejo do solo. As comparações das médias foram feitas pelo teste de Tukey a $5 \%$, utilizando-se o aplicativo computacional SISVAR (Ferreira, 2000). Foram feitas análises de correlação de Pearson, sendo a verificação da significância dos coeficientes de correlação (r) efetuada pelo teste $t$ de Student.

\section{RESULTADOS E DISCUSSÃO}

\section{Estoque de carbono e nitrogênio}

Os estoques de CO e NT nos diferentes sistemas de uso e manejo do solo são apresentados no quadro 3 . Para cálculo dos estoques de CO e NT, foi considerada a espessura da camada de solo; dessa forma, não foram avaliados os valores em relação às diferentes profundidades, uma vez que estas possuem diferentes espessuras.

$\mathrm{O}$ estoque de $\mathrm{CO}$ foi afetado de modo significativo pelos sistemas de uso e manejo do solo em todas as profundidades avaliadas (Quadro 3). De modo geral, considerando todas as profundidades de solo, os maiores valores de estoque de $\mathrm{CO}$ foram observados nos sistemas MTN e EUC, seguidos pelos sistemas PIN, PAS e MCM. Os sistemas de manejo com ausência ou menor revolvimento do solo apresentaram tendência em armazenar mais $\mathrm{CO}$, como observado nas profundidades de $0-10,20-40$ e $0-40 \mathrm{~cm}$. Paul \& Clark (1989) afirmam que o aumento do estoque de $\mathrm{CO}$ em solos submetidos a sistemas mais conservacionistas de manejo pode estar associado a dois fatores principais: proteção física dos compostos 
Quadro 3. Estoque de carbono orgânico e de nitrogênio total e densidade de um Latossolo Vermelho distroférrico típico submetido a diferentes sistemas de uso e manejo

\begin{tabular}{|c|c|c|c|c|}
\hline \multirow{2}{*}{ Sistema de uso e manejo ${ }^{(1)}$} & \multicolumn{4}{|c|}{ Profundidade (cm) } \\
\hline & $0-10$ & $10-20$ & $20-40$ & $0-40$ \\
\hline & \multicolumn{4}{|c|}{ Estoque de carbono $\left(\mathrm{t} \mathrm{ha}^{-1}\right)$} \\
\hline MTN & 33,95 a & $16,20 \mathrm{~b}$ & $40,45 \mathrm{~b}$ & $90,60 \mathrm{ab}$ \\
\hline EUC & $29,48 \mathrm{a}$ & $26,27 \mathrm{ab}$ & $49,51 \mathrm{a}$ & $105,28 \mathrm{a}$ \\
\hline PIN & $20,44 \mathrm{~b}$ & $30,60 \mathrm{a}$ & $36,81 \mathrm{~b}$ & $87,87 \mathrm{~b}$ \\
\hline PAS & $27,32 \mathrm{~b}$ & $24,67 \mathrm{ab}$ & $42,59 \mathrm{~b}$ & $94,60 \mathrm{ab}$ \\
\hline $\mathrm{MCM}$ & $20,44 \mathrm{~b}$ & $30,36 \mathrm{a}$ & $35,76 \mathrm{~b}$ & $86,57 \mathrm{~b}$ \\
\hline \multirow[t]{2}{*}{ MPC } & $16,35 \mathrm{c}$ & $16,14 \mathrm{~b}$ & $29,95 \mathrm{c}$ & $62,44 \mathrm{c}$ \\
\hline & \multicolumn{4}{|c|}{ Estoque de nitrogênio $\left(\mathrm{t} \mathrm{ha}^{-1}\right)$} \\
\hline MTN & $2,79 \mathrm{a}$ & $1,57 \mathrm{a}$ & $3,62 \mathrm{ab}$ & $7,98 \mathrm{ab}$ \\
\hline EUC & $2,51 \mathrm{a}$ & $1,91 \mathrm{a}$ & $4,48 \mathrm{a}$ & 8,89 a \\
\hline PIN & $2,69 \mathrm{a}$ & $1,73 \mathrm{a}$ & $3,73 \mathrm{ab}$ & $8,16 \mathrm{ab}$ \\
\hline PAS & $2,56 \mathrm{a}$ & $2,20 \mathrm{a}$ & $3,85 \mathrm{ab}$ & $8,60 \mathrm{ab}$ \\
\hline $\mathrm{MCM}$ & $2,38 \mathrm{a}$ & $1,85 \mathrm{a}$ & $3,45 \mathrm{~b}$ & $7,66 \mathrm{~b}$ \\
\hline \multirow[t]{2}{*}{$\mathrm{MPC}$} & $2,01 \mathrm{a}$ & $2,14 \mathrm{a}$ & $3,65 \mathrm{ab}$ & $7,80 \mathrm{~b}$ \\
\hline & \multicolumn{4}{|c|}{ Densidade do solo $\left(\mathrm{kg} \mathrm{dm}^{-3}\right)$} \\
\hline MTN & $0,88 \mathrm{c}$ & $0,88 \mathrm{c}$ & $0,94 \mathrm{~d}$ & - \\
\hline EUC & $1,02 \mathrm{bc}$ & $1,06 \mathrm{~b}$ & $1,07 \mathrm{~b}$ & - \\
\hline PIN & $1,11 \mathrm{~b}$ & $1,15 \mathrm{ab}$ & $1,07 \mathrm{~b}$ & - \\
\hline PAS & $1,09 \mathrm{~b}$ & $1,07 \mathrm{~b}$ & $1,03 \mathrm{c}$ & - \\
\hline $\mathrm{MCM}$ & $1,22 \mathrm{a}$ & $1,20 \mathrm{a}$ & $1,17 \mathrm{a}$ & - \\
\hline MPC & $1,11 \mathrm{~b}$ & $1,19 \mathrm{a}$ & $1,14 \mathrm{a}$ & - \\
\hline
\end{tabular}

(1) MTN: mata nativa; EUC: eucalipto; PIN: pinus; PAS: pastagem; MCM: milho cultivado no sistema de cultivo mínimo; MPC: milho cultivado no sistema plantio convencional. Para ambos os atributos, dentro de cada profundidade, as médias seguidas da mesma letra não diferem entre si pelo teste de Tukey $(p<0,05)$.

orgânicos contra a decomposição microbiana, favorecida pela oclusão do CO nos agregados do solo; e proteção química dos compostos orgânicos por meio da interação destes com os minerais e cátions do solo, o que dificulta a sua decomposição.

O estoque de $\mathrm{CO}$ nas áreas de reflorestamento com eucalipto e pinus esteve próximo ou acima dos valores encontrados no sistema MTN (Quadro 3), embora o teor de $\mathrm{CO}$ fosse menor nos primeiros (Quadro 5). O maior estoque de CO nos sistemas EUC e PIN pode ser explicado pela maior densidade do solo nessas áreas (Quadro 3). Os dados observados na literatura indicam tendências diferentes para mudanças nos estoques de $\mathrm{CO}$ do solo em áreas sob reflorestamento nos trópicos. Embora alguns autores relatem redução nos estoques de $\mathrm{CO}$ em áreas de plantação de eucalipto e pinus (Madeira et al., 1989; Fonseca et al., 1993), em outros estudos não foi observada nenhuma alteração (Lima et al., 1995; Turner \& Lambert, 2000). Zinn et al. (2002), em estudo realizado em Latossolo argiloso do Cerrado cultivado com eucalipto e pinus, observaram valores de estoque de CO de 51,8 e $61 \mathrm{Mg} \mathrm{ha}^{-1}$, respectivamente, para a profundidade de 0-40 cm, valores esses abaixo dos descritos no presente trabalho. Esses resultados contraditórios encontrados em literatura certamente estão associados à grande variabilidade nas condições experimentais, como clima, tipo e preparo do solo e manejo e idades das florestas, que afetam o crescimento das árvores e a decomposição dos resíduos depositados no solo (Zinn et al., 2002).

No Brasil, as áreas sob pastagem, principalmente de gramíneas de origem africana, estão crescendo em todas as regiões. O levantamento publicado por Boddey et al. (2001) revela que mais de 80 milhões de hectares estão ocupados por pastagens do gênero Brachiaria atualmente no Brasil. Analisando os dados do quadro 3, é possível observar que, com exceção da profundidade de $0-10 \mathrm{~cm}$, o sistema PAS apresentou estoque de $\mathrm{CO}$ semelhante ao do sistema MTN, com 
valores numericamente superiores nas camadas de 10-20, 20-40 e 0-40 cm. Esses resultados podem ser atribuídos ao sistema radicular mais desenvolvido e bem distribuído das gramíneas sob pastagem, o que favorece a elevada deposição de $\mathrm{C}$ ao solo na forma de raízes. Segundo Teixeira \& Bastos (1989), as pastagens, em geral, apresentam distribuição regular do sistema radicular até um metro de profundidade, com $46 \%$ das raízes na camada superficial do solo (0$10 \mathrm{~cm}), 18,6 \%$ na camada de $10-20 \mathrm{~cm}, 22,8 \%$ na de 20-40 cm e 12,4\% na de 40-100 cm.

Nas profundidades de 0-10, 20-40 e 0-40 cm, os menores estoques de $\mathrm{CO}$ foram observados nas áreas sob cultivo de milho; entre estas, o estoque de CO foi significativamente inferior no sistema com maior revolvimento do solo (MPC) (Quadro 3). É provável que o revolvimento do solo, homogeneizando as camadas superficiais pelas operações de aração e gradagem, tenha contribuído para ocorrência desse efeito. Souza \& Melo (2003), estudando o impacto de diferentes sistemas de produção do milho sobre a dinâmica do $\mathrm{C}$ do solo, também observaram menores valores de estoque de $\mathrm{CO}$ no solo cultivado no sistema convencional, comparativamente aos valores obtidos nos sistemas onde os restos culturais eram mantidos na superfície do solo.

Os resultados de estoque de $\mathrm{CO}$ apresentados no quadro 3 revelam diferenças entre os sistemas avaliados nas diferentes profundidades de amostragem. $\mathrm{Na}$ profundidade de $0-10 \mathrm{~cm}$ obteve-se a seguinte seqüência para os valores de estoque de CO: MTN > PAS = MCM. A mesma comparação efetuada na profundidade de $0-40 \mathrm{~cm}$ apresentou a seguinte seqüência: $\mathrm{MTN}=\mathrm{PAS}=\mathrm{MCM}$. Assim, para uma estimativa confiável do estoque de $\mathrm{CO}$ em estudos que avaliam diferentes sistemas de uso e manejo, as amostras de solo devem ser coletadas até maiores profundidades, a fim de possibilitar a indicação de sistemas capazes de preservar e, ou, aumentar os estoques de $\mathrm{CO}$ do solo.
Em geral, houve poucas alterações nos estoques de NT do solo (Quadro 3). Somente na profundidade de 20-40 cm e para o somatório dos estoques de NT nas diferentes profundidades do solo $(0-40 \mathrm{~cm})$ foram observadas diferenças significativas entre os sistemas de uso e manejo avaliados. Os estoques de NT na camada de 0-40 cm variaram de 7,66 (MCM) a $8,89 \mathrm{Mg} \mathrm{ha}^{-1}$ (EUC). O aumento do estoque de NT nos sistemas MTN, EUC, PIN e PAS está provavelmente associado ao maior volume de resíduos vegetais retornados ao solo e, também, aos maiores estoques de CO nesses sistemas (Quadro 3). O maior armazenamento de $\mathrm{CO}$ implica em maior disponibilidade de NT, uma vez que mais de $95 \%$ do NT do solo está presente na forma orgânica (Camargo et al., 1999).

Mais informativo que os valores absolutos dos estoques de CO é a variação destes em relação ao sistema referência (MTN) ( $\Delta$ EstC) (Figura 1$)$, sendo esses valores uma estimativa do incremento ou da redução do estoque de CO do solo. Todos os sistemas de uso e manejo do solo resultaram em redução nos estoques de $\mathrm{CO}$ na profundidade de $0-10 \mathrm{~cm}$, em relação ao sistema MTN, o que indica a susceptibilidade da oxidação do CO das camadas superficiais dos solos quando estes são submetidos a diferentes sistemas de uso e manejo. As reduções nos estoques de $\mathrm{CO}$ na profundidade de 0-10 cm foram de 13,2, 39,8, 19,5, 39,8 e 48,1 \% para EUC, PIN, PAS, MCM e MPC, respectivamente (Figura 1). Com exceção do sistema MPC, nos demais sistemas de manejo a redução nos estoques de $\mathrm{CO}$ foi similar ou inferior ao percentual de $40 \%$ estimado por Scholes et al. (1997) para solos tropicais cultivados.

Nas demais profundidades de solo avaliadas, as variações nos estoques de $\mathrm{CO}$ apresentaram valores positivos nos sistemas EUC (10-20 e 20-40 cm), PIN (10-20 cm), PAS (10-20 e 20-40 cm) e MCM (10$20 \mathrm{~cm}$ ) (Figura 1), demonstrando o potencial desses sistemas em atuar como drenos de C- $\mathrm{CO}_{2}$ da atmosfera. No sistema MPC, os valores de $\Delta$ EstC

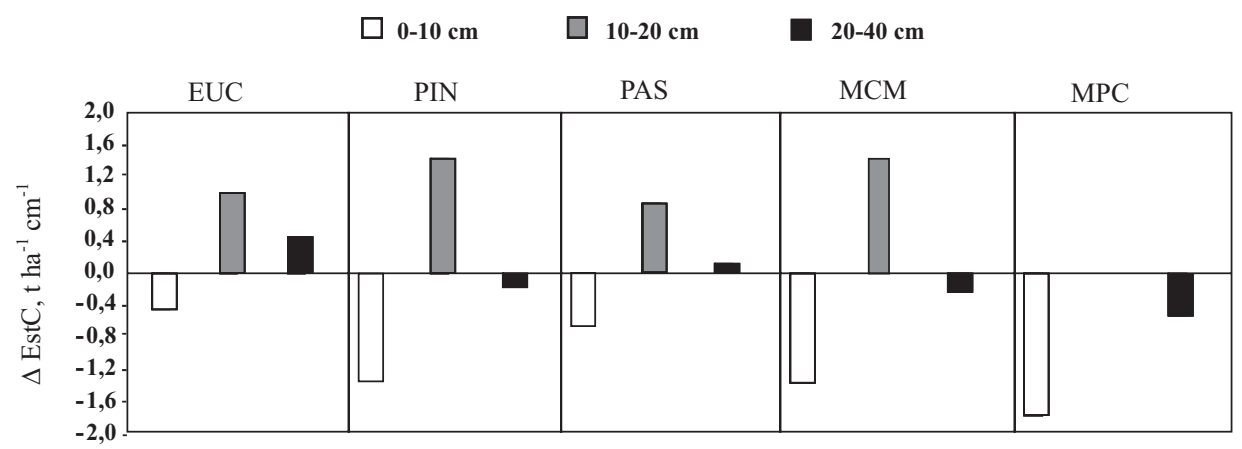

Figura 1. Variação do estoque de carbono orgânico ( $\Delta \mathrm{EstC})$ nas profundidades de 0-10, 10-20 e 20-40 cm em relação ao sistema mata nativa (MTN) num Latossolo Vermelho distroférrico típico submetido a diferentes sistemas de uso e manejo: EUC: eucalipto; PIN: pinus; PAS: pastagem; MCM: milho no sistema de cultivo mínimo; MPC: milho no sistema plantio convencional. Valores positivos indicam aumento no estoque de CO em relação ao sistema MTN. 
foram negativos para todas as profundidades avaliadas, com pequena tendência de acúmulo de CO na profundidade de $10-20 \mathrm{~cm}$. No sistema plantio convencional, o revolvimento constante do solo e as melhores condições de aeração propiciam a rápida decomposição da MO (Mielniczuk et al., 2003). O menor valor de $\Delta$ EstC na profundidade de $0-10 \mathrm{~cm}$ no sistema MPC $\left(-1,8 \mathrm{t} \mathrm{ha}^{-1} \mathrm{~cm}^{-1}\right)$ coincide com a faixa de trabalho das grades pesadas, utilizadas no preparo da área para plantio do milho. Nesse mesmo sistema, as menores perdas de CO na profundidade de 10$20 \mathrm{~cm}\left(-0,005 \mathrm{t} \mathrm{ha}^{-1} \mathrm{~cm}^{-1}\right)$ podem estar associadas à incorporação dos resíduos vegetais, aumentando a entrada de $\mathrm{C}$ no solo.

Levando em consideração todas as profundidades do solo e tomando-se o sistema MTN como referência, nos sistemas EUC e PAS houve incremento de 14,7 e 4,0 $\mathrm{t} \mathrm{ha}^{-1}$, respectivamente, no estoque de $\mathrm{CO}$, enquanto nos sistemas PIN, MCM e MPC a redução foi de 2,8, 4,0 e 28,2 $\mathrm{t} \mathrm{ha}^{-1}$, respectivamente (Figura 1). Considerando um fator de conversão de $\mathrm{C}$ para $\mathrm{CO}_{2}$ de 3,67 (massa molar do $\mathrm{CO}_{2}$ /massa molar do $\mathrm{C}$ ), nos sistemas onde foram observadas reduções nos estoques de $\mathrm{C}$ houve liberação total de $128,5 \mathrm{t} \mathrm{ha}^{-1}$ de $\mathrm{C}-\mathrm{CO}_{2}$ para a atmosfera.

\section{Fracionamento físico-densimétrico da matéria orgânica do solo}

No quadro 4 são apresentados os teores de CO das frações leve $\left(\mathrm{C}_{\mathrm{FL}}\right)$ e pesada (C-areia, $\mathrm{C}$-silte e $\mathrm{C}$-argila) da MOS. A taxa de recuperação do CO do solo, após fracionamento, variou de 87,7 a 122,1\% (média de $102 \%$ ), na profundidade de $0-5 \mathrm{~cm}$, e de 101,9 a $124,6 \%$ (média de $113 \%$ ), na profundidade de 0-10 cm. Roscoe \& Buurman (2003) obtiveram valores de recuperação do $\mathrm{CO}$ do solo pelo fracionamento físicodensimétrico variando de 89 a $101 \%$, enquanto Freixo et al. (2002), trabalhando com Latossolo VermelhoAmarelo do Cerrado, verificaram valores oscilando entre 76 e $96 \%$. A maior amplitude de variação na taxa de recuperação obtida no presente trabalho pode estar relacionada ao maior teor de argila do solo, favorecendo uma maior agregação e estabilização do CO.

Dentre os sistemas de uso e manejo do solo, a MTN, o EUC e o PIN, nas duas profundidades de solo em estudo, apresentaram os maiores teores de $\mathrm{C}_{\mathrm{FL}}$, sendo este um indício de que, nesses sistemas, ocorre maior proteção física da fração leve da MOS. Os teores de $\mathrm{C}_{\mathrm{FL}}$ tiveram grande redução nas áreas de cultivo de milho (Quadro 4). Em relação ao sistema MTN, que apresentou $3,5 \mathrm{~g} \mathrm{~kg}^{-1}$ de $\mathrm{C}_{\mathrm{FL}}$, a diminuição nos teores de $\mathrm{C}_{\mathrm{FL}}$ nos sistemas MCM e MPC foi de 86 e $91 \%$, respectivamente, na profundidade de $0-5 \mathrm{~cm}$. Esses resultados estão de acordo com Freixo et al. (2002), que observaram redução média nos teores de $\mathrm{C}_{\mathrm{FL}}$ de $85 \%$ em Latossolo sob cultivo de milho nos sistemas plantio direto e convencional, em relação ao mesmo solo sob Cerrado nativo (referência do estudo).

Nos sistemas MTN, EUC e PIN, a fonte de substâncias orgânicas está associada, principalmente, à deposição natural de resíduos de plantas, que

Quadro 4. Teores de carbono orgânico nas frações físico-densimétricas de amostras coletadas nas profundidades de 0-5 e 0-10 cm de um Latossolo Vermelho distroférrico típico submetido a diferentes sistemas de uso e manejo ${ }^{(1)}$

\begin{tabular}{|c|c|c|c|c|c|c|c|}
\hline \multirow{2}{*}{ Profundidade } & \multirow{2}{*}{ C-Fração ${ }^{(2)}$} & \multicolumn{6}{|c|}{ Sistema $^{(3)}$} \\
\hline & & MTN & EUC & PIN & PAS & MCM & MPC \\
\hline \multicolumn{8}{|l|}{$\mathrm{cm}$} \\
\hline \multirow[t]{4}{*}{$0-5$} & FL & $3,5(0,3)$ & $5,1(0,7)$ & $4,6(0,3)$ & $1,0(0,2)$ & $0,5(0,1)$ & $0,3(0,1)$ \\
\hline & Areia & $1,2(0,2)$ & $1,2(0,1)$ & $1,8(0,1)$ & $1,0(0,06)$ & $0,6(0,05)$ & $0,3(0,06)$ \\
\hline & Silte & $27,1(2,2)$ & $11,0(0,3)$ & $12,6(1,3)$ & $7,9(1,8)$ & $10,1(0,7)$ & $4,4(0,3)$ \\
\hline & Argila & $26,9(2,6)$ & $26,1(3,9)$ & $22,6(4,0)$ & $20,5(3,3)$ & $11,7(1,5)$ & $9,1(2,2)$ \\
\hline Recuperação (\%) ${ }^{(4)}$ & & 122,1 & 102,3 & 100,5 & 87,7 & 106,4 & 94,0 \\
\hline \multirow[t]{4}{*}{$0-10$} & FL & $5,8(0,8)$ & $2,3(0,4)$ & $2,5(0,2)$ & $1,0(0,2)$ & $0,2(0,02)$ & $0,3(0,01)$ \\
\hline & Areia & $1,1(0,1)$ & $0,8(0,03)$ & $0,7(0,3)$ & $1,0(0,04)$ & $0,4(0,08)$ & $0,4(0,09)$ \\
\hline & Silte & $17,5(1,3)$ & $9,9(1,2)$ & $7,6(1,1)$ & $10,1(1,5)$ & $7,8(0,8)$ & $5,3(0,3)$ \\
\hline & Argila & $19,3(0,8)$ & $17,4(0,2)$ & $11,3(0,3)$ & $15,3(0,6)$ & $10,2(0,7)$ & $8,6(0,9)$ \\
\hline Recuperação (\%) & & 115 & 110,7 & 124,6 & 112,8 & 113,2 & 101,9 \\
\hline
\end{tabular}

(1) Valores entre parênteses referem-se ao erro-padrão da média (n=3). ${ }^{(2)}$ FL: carbono associado à fração leve; areia, silte e argila: carbono associado às frações granulométricas areia, silte e argila. ${ }^{(3)}$ MTN: mata nativa; EUC: eucalipto; PIN: pinus; PAS: pastagem; MCM: milho no sistema de cultivo mínimo; MPC: milho no sistema plantio convencional. ${ }^{(4)}$ Relação entre o teor de CO do solo e a soma do CO determinado em cada fração. 
alcançam o solo na forma de folhas, galhos e outros fragmentos orgânicos, bem como substâncias orgânicas derivadas da decomposição das raízes (Pohlman \& Mccoll, 1988). Rovira \& Vallejo (2002) relatam que a resistência à hidrólise ácida é maior para os polímeros orgânicos recalcitrantes (ligninas, suberinas, resinas e ceras). Assim, os maiores teores de $\mathrm{C}_{\mathrm{FL}}$ encontrados no solo dos sistemas MTN, EUC e PIN podem também estar associados à qualidade dos resíduos adicionados ao solo, que, provavelmente, apresentam maiores proporções de $\mathrm{C}$ mais resistente do ponto de vista químico.

O carbono presente na fração pesada correspondeu, em média, a $94 \%$ do CO do solo (Figura 2), aumentando a proporção na seguinte ordem: $\mathrm{MCM}=\mathrm{MPC}>$ PAS > MTN > PIN > EUC, com valores próximos de $98 \%$ nos sistemas MCM e MPC. A fração mais lábil da $\operatorname{MOS}\left(\mathrm{C}_{\mathrm{FL}}\right)$ representou uma pequena percentagem do $\mathrm{CO}$ do solo, uma vez que, na profundidade de $0-5 \mathrm{~cm}$, o $\mathrm{C}_{\mathrm{FL}}$ representou de 2,3 (MPC) a $12 \%$ (EUC) do CO do solo, e de 1,1 (MCM) a 14,8\% (MTN) na profundidade de $0-10 \mathrm{~cm}$ (Figura 2). Os maiores percentuais de $\mathrm{C}_{\mathrm{FL}}$ foram observados nos sistemas MTN, EUC e PAS. Na área de mata, na profundida-

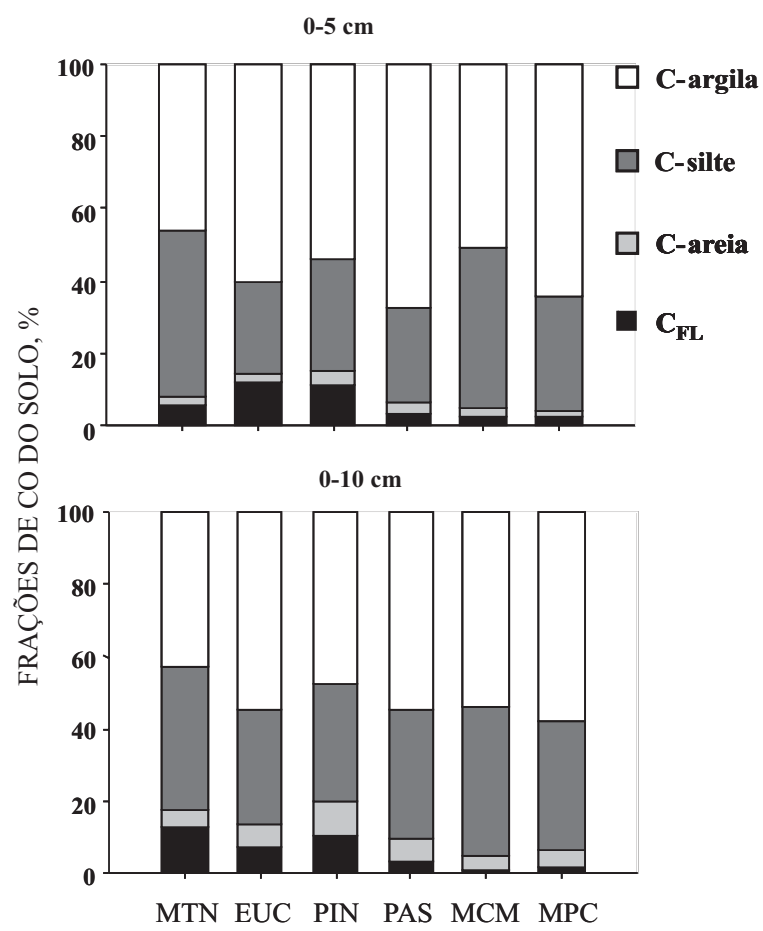

Figura 2. Percentagem do carbono orgânico nas frações leve $\left(C_{F L}\right)$ e pesada (C-areia, C-silte e $C$ argila) nas profundidades de 0-5 e 0-10 cm de Latossolo Vermelho distroférrico típico submetido a diferentes sistemas de uso e manejo. MTN: mata nativa; EUC: eucalipto; PIN: pinus; PAS: pastagem; MCM: milho no sistema de cultivo mínimo; MPC: milho no sistema plantio convencional. de de $0-10 \mathrm{~cm}$, a percentagem de $\mathrm{C}_{\mathrm{FL}}$ foi 6 e 14 vezes maior que aquela obtida nos sistemas com maior revolvimento do solo (MCM e MPC, respectivamente).

A pequena contribuição do $\mathrm{C}_{\mathrm{FL}}$ para o $\mathrm{CO}$ do solo, principalmente nos sistemas MCM e MPC, provavelmente está associada à redução no aporte de resíduo e ao aumento na taxa de decomposição dessa fração em solos menos estruturados, mais oxigenados, com temperaturas elevadas, boa disponibilidade de água, calagem e adubação (Christensen, 2000). Outra explicação para a pequena participação do $\mathrm{C}_{\mathrm{FL}}$ no $\mathrm{CO}$ do solo reside no fato de que o único mecanismo de proteção dessa fração é a recalcitrância dos seus materiais constituintes, o que torna o $\mathrm{C}_{\mathrm{FL}}$ mais disponível para a microbiota que a fração pesada da MOS (Roscoe \& Machado, 2002). Para solos argilosos de regiões temperadas, Parfitt et al. (1997) relataram percentagem de $\mathrm{C}_{\mathrm{FL}}$ variando de 16 a $39 \%$ do $\mathrm{CO}$ do solo. Entretanto, para Latossolos argilosos de regiões tropicais sob diferentes sistemas de manejo (floresta, Cerrado e pastagem), Golchin et al. (1995) e Freixo et al. (2002) observaram percentagens de $\mathrm{C}_{\mathrm{FL}}$ variando de 1 a $4 \%$ do $\mathrm{CO}$ do solo, valores esses semelhantes aos da figura 2 .

O acúmulo de $\mathrm{CO}$ na fração pesada, como resultado da interação positiva entre as partículas de argila e a MOS, é bem documentado na literatura para solos argilosos (Christensen, 2000). No Latossolo em estudo, as frações orgânicas associadas às partículas de areia contribuíram com cerca de 2,0 a $4,3 \%(0-5 \mathrm{~cm})$ e de 3,7 a $9,3 \%(0-10 \mathrm{~cm})$ do total de CO do solo, seguida das frações silte, com 25,3 a 46,2 \% (0-5 cm) e 31,3 a $41,3 \%$ (0-10 cm), e argila, que contribuiu, em média, com mais 57 e $52 \%$ do $\mathrm{CO}$ do solo nas profundidades de $0-5$ e $0-10 \mathrm{~cm}$, respectivamente (Figura 2). Os baixos teores e proporção do $\mathrm{CO}$ do solo associado à fração areia está relacionado, segundo Christensen (1992), à reduzida superfície específica e densidade de carga superficial das areias, fazendo com que esta fração apresente pouco ou nenhum material orgânico fortemente ligado, sendo pobre em complexos organominerais. A proporção de $\mathrm{CO}$ nas partículas mais finas (silte e argila) aumentou com a intensidade de cultivo do solo, o que implica menor quantidade de formas de CO prontamente disponíveis aos microrganismos, frações essas que estão mais associadas ao $\mathrm{C}_{\mathrm{FL}}$ e C-areia. Em Latossolo argiloso de baixa fertilidade localizado em região tropical, Guggenberger et al. (1995) encontraram percentagem de C-areia, C-silte e C-argila variando de $2-4 \%$, $39-45 \%$ e $51-59 \%$ do CO do solo, valores esses similares aos encontrados neste estudo.

Em relação ao sistema MTN, as reduções nos teores de CO na fração pesada (C-areia + C-silte + C-argila) nos sistemas EUC, PIN, PAS, MPC e MCM foram de $31,33,47,59$ e $75 \%$ e de $26,48,30,51$ e $62 \%$, respectivamente, nas profundidades de $0-5$ e $0-10 \mathrm{~cm}$, mostrando ser a fração pesada menos sensível, em relação ao $\mathrm{C}_{\mathrm{FL}}$, a alterações nos sistemas de uso e 
manejo do solo. Na profundidade de $0-10 \mathrm{~cm}$, observou-se aumento na proporção de $\mathrm{CO}$ nas frações silte e argila em MPC, o que poderia ser explicado pelo efeito da incorporação dos resíduos vegetais, propiciando maior estabilização da MOS nessas partículas.

\section{Carbono da biomassa microbiana do solo}

Os dados de $\mathrm{C}$ da biomassa microbiana $\left(\mathrm{C}_{\text {mic }}\right)$ apresentaram comportamento semelhante ao das demais formas de CO do solo (Quadro 5). O sistema MTN apresentou teor elevado de $\mathrm{C}_{\text {mic }}\left(1.029,5 \mathrm{mg} \mathrm{kg}^{-1}\right)$, significativamente maior do que os valores encontrados para os demais sistemas. Tomando o sistema MTN como referência, observou-se redução nos valores de $\mathrm{C}_{\text {mic }}$ da ordem de $28,35,40,68$ e $66 \%$, respectivamente, nos sistemas EUC, PIN, PAS, MCM e MPC.

Não foram observadas diferenças significativas entre os sistemas EUC, PIN e PAS quanto ao teor de $\mathrm{C}_{\text {mic. }}$. Considerando os sistemas EUC e PIN com maior presença de gramíneas no sub-bosque, esperava-se que estes apresentassem maiores valores de $\mathrm{C}_{\text {mic. }}$ Os menores valores de $\mathrm{C}_{\text {mic }}$ no sistema $\mathrm{EUC}$ devem-se, provavelmente, à presença de substâncias com atividade antimicrobiana encontradas na necromassa do eucalipto, além da ocorrência de compostos fenólicos que apresentam alta toxicidade microbiana (Siqueira et al., 1991). Segundo Luizão et al. (1994), a redução nos teores de $\mathrm{C}_{\text {mic }}$ em solos sob pastagem pode ser explicada pelas modificações na estrutura física do solo decorrentes da compactação provocada pelo pisoteio da área pelo rebanho bovino. Geraldes et al. (1995) observaram redução, em relação ao sistema referência (mata natural), de $41 \%$ no $\mathrm{C}_{\text {mic }}$ em pastagem implantada há mais de 15 anos - valor semelhante ao encontrado neste trabalho (40\%) para a pastagem de braquiária com 12 anos de implantação.

A percentagem de $\mathrm{C}_{\text {mic }}$ em relação $\mathrm{CO}$ do solo $\left(\mathrm{C}_{\text {mic }} / \mathrm{CO}\right)$, ou quociente microbiano, variou de $1,53 \%$, no MCM, até 2,29\%, no MPC (Quadro 5). Esses valores estão na mesma ordem de magnitude daqueles observados por Leite et al. (2003) para diferentes sistemas agrícolas (1 a $2 \%$ ) localizados no Estado de Minas Gerais. Jenkinson \& Ladd (1981) consideram normal valores da relação $\mathrm{C}_{\text {mic }} / \mathrm{CO}$ entre 1 e $4 \%$, sendo estes dependentes de clima, $\mathrm{pH}$, sistemas de cultura, preparo do solo e quantidade e qualidade do aporte de resíduos ao solo (Lutzow et al., 2002). Por esse motivo, a relação $\mathrm{C}_{\text {mic }} / \mathrm{CO}$ não deve ser analisada isoladamente como um indicador da qualidade e da recuperação da MOS. Os valores mais elevados da relação $\mathrm{C}_{\text {mic }} / \mathrm{CO}$ obtidos em MPC podem estar relacionados à maior decomposição do CO nesse sistema, em razão da incorporação dos resíduos vegetais e maior aeração do solo.

Quadro 5. Teores de carbono orgânico (CO), carbono da biomassa microbiana $\left(\mathrm{C}_{\mathrm{mic}}\right)$ e relações $\mathrm{C}_{\mathrm{mic}} / \mathrm{CO}$, carbono associado à fração leve $\left(\mathrm{C}_{\mathrm{FL}}\right)$ e $\mathrm{CO}\left(\mathrm{C}_{\mathrm{FL}} / \mathrm{CO}\right), \mathrm{C}_{\mathrm{mic}} / \mathrm{C}_{\mathrm{FL}}$ e $\mathrm{CO}$ e nitrogênio total $(\mathrm{CO} / \mathrm{NT})$, nas profundidades de 0-5 e 0-10 cm de Latossolo Vermelho distroférrico típico submetido a diferentes sistemas de uso e manejo

\begin{tabular}{|c|c|c|c|c|c|c|}
\hline Sistema $^{(1)}$ & $\mathrm{CO}$ & $\mathrm{C}_{\mathrm{mic}}$ & $\mathrm{C}_{\mathrm{mic}} / \mathrm{CO}$ & $\mathrm{C}_{\mathrm{FL}} / \mathrm{CO}$ & $\mathrm{C}_{\mathrm{mic}} / \mathrm{C}_{\mathrm{FL}}$ & $\mathrm{CO} / \mathrm{NT}$ \\
\hline & $\mathrm{g} \mathrm{kg}^{-1}$ & $\mathrm{mg} \mathrm{kg}^{-1}$ & $\ldots$ & $\%$ & + & \\
\hline & \multicolumn{6}{|c|}{$0-5 \mathrm{~cm}$} \\
\hline MTN & $48,4 \mathrm{a}$ & 1029,5 a & $2,12 \mathrm{a}$ & $7,3 \mathrm{~b}$ & $0,29 \mathrm{c}$ & $13,4 \mathrm{~b}$ \\
\hline EUC & $42,4 \mathrm{~b}$ & $735,3 \mathrm{~b}$ & $1,73 \mathrm{a}$ & $12,0 \mathrm{a}$ & $0,14 \mathrm{~d}$ & $13,2 \mathrm{~b}$ \\
\hline PIN & $41,4 \mathrm{~b}$ & $672,5 \mathrm{~b}$ & $1,64 \mathrm{a}$ & $11,1 \mathrm{a}$ & $0,15 \mathrm{~d}$ & $15,5 \mathrm{a}$ \\
\hline PAS & $34,9 \mathrm{bc}$ & $623,4 \mathrm{~b}$ & $1,79 \mathrm{a}$ & $2,9 \mathrm{c}$ & $0,63 \mathrm{~b}$ & $14,1 \mathrm{a}$ \\
\hline $\mathrm{MCM}$ & $21,5 \mathrm{c}$ & $327,7 \mathrm{c}$ & $1,53 \mathrm{a}$ & $2,5 \mathrm{c}$ & $0,62 \mathrm{~b}$ & $9,6 \mathrm{~b} \mathrm{c}$ \\
\hline \multirow[t]{2}{*}{ MPC } & $15,1 \mathrm{c}$ & $348,3 \mathrm{c}$ & $2,29 \mathrm{a}$ & $2,3 \mathrm{c}$ & $1,01 \mathrm{a}$ & $8,5 \mathrm{c}$ \\
\hline & \multicolumn{6}{|c|}{$0-10 \mathrm{~cm}$} \\
\hline MTN & 38,9 a & - & - & $14,8 \mathrm{a}$ & - & $12,2 \mathrm{a}$ \\
\hline EUC & $29,0 \mathrm{~b}$ & - & - & $7,8 \mathrm{~b}$ & - & $11,7 \mathrm{a}$ \\
\hline PIN & $19,0 \mathrm{c}$ & - & - & $13,4 \mathrm{a}$ & - & $7,7 \mathrm{c}$ \\
\hline PAS & $25,0 \mathrm{~b}$ & - & - & $4,0 \mathrm{c}$ & - & $10,7 \mathrm{~b}$ \\
\hline $\mathrm{MCM}$ & $16,6 \mathrm{~d}$ & - & - & $1,1 \mathrm{~d}$ & - & $8,6 \mathrm{c}$ \\
\hline MPC & $14,6 \mathrm{~d}$ & - & - & $2,3 \mathrm{~cd}$ & - & $8,2 \mathrm{c}$ \\
\hline
\end{tabular}

(1) MTN: mata nativa; EUC: eucalipto; PIN: pinus; PAS: pastagem; MCM: milho cultivado no sistema de cultivo mínimo; MPC: milho cultivado no sistema plantio convencional. Médias seguidas da mesma letra, dentro de cada profundidade do solo e atributo avaliado, não diferem entre si pelo teste de Tukey $(p<0,05)$. 
A relação CO/NT do solo variou de 8,5 (MPC) a $13,4 / 1$ (MTN) e de 7,7 (PAS) a 12,2/1 (MTN) para as amostras coletadas nas profundidades de $0-5$ e 0-10 cm, respectivamente (Quadro 5). Para solos de regiões tropicais não revolvidos existe equilíbrio na relação CO/NT em torno de 10 a 15/1 (Stevenson, 1994). Os baixos valores dessa relação observados em MPC e MCM podem ser devidos ao alto valor de $\mathrm{pH}$ e à ausência de alumínio no solo (Quadro 2), fatores que favorecem o aumento da decomposição da MOS (Stevenson, 1994). Apesar de não haver informações detalhadas sobre o manejo da fertilidade do solo nos sistemas cultivados com milho em anos muito anteriores ao da amostragem, é possível afirmar que as adubações nitrogenadas efetuadas na cultura do milho ao longo dos anos criaram condições favoráveis à elevação dos teores de NT do solo e conseqüente redução dos valores da relação CO/NT.

Os teores de $\mathrm{C}_{\text {mic }}$ correlacionaram-se com os teores de $\mathrm{CO}$ e com as frações $\mathrm{C}$-silte e $\mathrm{C}$-argila do solo (Quadro 6), com coeficientes de correlação (r) acima de $0,85^{* *}$. A correlação negativa entre $C_{\text {mic }}$ e $C_{F L}$ pode ser explicada pela pequena percentagem do $\mathrm{CO}$ presente nesta fração e pela redução mais acentuada do $\mathrm{C}_{\mathrm{FL}}$ em relação aos teores de $\mathrm{CO}$, C-silte e $\mathrm{C}$-argila. A alta correlação entre $\mathrm{CO}$ e $\mathrm{C}$-argila $\left(\mathrm{r}=0,99^{* *}\right)$ reafirma os resultados da figura 2 , em que se pode observar que a maior parte do $\mathrm{CO}$ do solo está presente na fração argila, sendo, por esse motivo, mais protegido química e fisicamente e menos sensível às alterações nos sistemas de manejo do solo. $\mathrm{O} \mathrm{C}_{\mathrm{FL}}$ correlacionou-se com o C-areia. Gregorich \& Ellert (1993) afirmam ser o material orgânico recuperado na fração areia também chamado de matéria macrorgânica ou MO particulada, constituído basicamente de MO não complexada ou livre, o que a assemelha à fração leve obtida pelo fracionamento densimétrico.

$\mathrm{Na}$ figura 3 são apresentados alguns atributos do solo avaliados nas amostras coletadas nos diferentes sistemas de uso e manejo. Os atributos do solo em MTN foram utilizados como referência. Verifica-se que, nos sistemas com maior aporte de resíduos (entrada de $\mathrm{C}$ fotossintetizado) e menor revolvimento, o solo apresentou-se num estado mais próximo ao da referência, surgindo atributos emergentes, como o aumento do $\mathrm{C}$ associado à fração leve $\left(\mathrm{C}_{\mathrm{FL}}\right)$. Os dados da figura 3 também mostram que as maiores alterações entre os atributos avaliados ocorreram nos teores de $\mathrm{C}_{\mathrm{mic}}$ e $\mathrm{C}_{\mathrm{FL}}$, comparativamente às alterações nos valores de EstN e $\mathrm{C}_{\mathrm{FP}}$ (C associado à fração pesada). Em modelos de simulação da dinâmica da MOS, como o Century (Parton et al., 1987), o $\mathrm{C}_{\text {mic }}$ e o $\mathrm{C}_{\mathrm{FL}}$

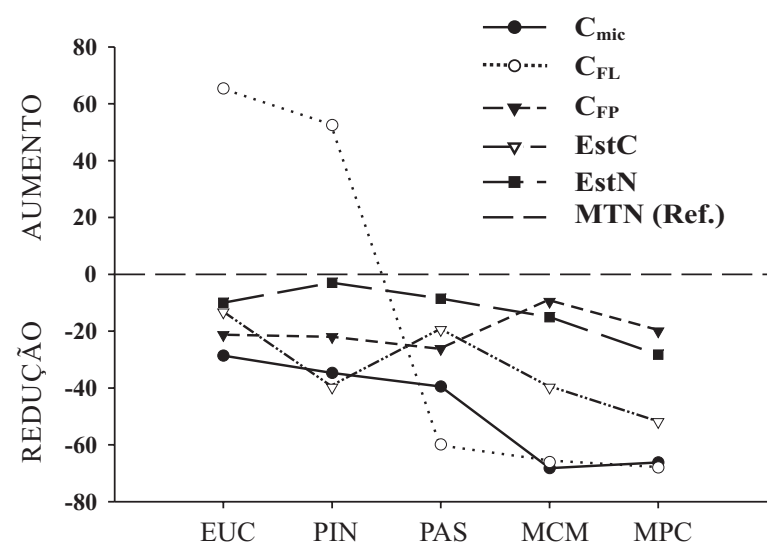

Figura 3. Atributos de Latossolo Vermelho distroférrico típico nos sistemas eucalipto (EUC), pinus (PIN), pastagem (PAS), milho no sistema de cultivo mínimo (MCM) e milho no sistema plantio convencional (MPC), em comparação ao sistema mata nativa (MTN). Cmic: carbono da biomassa microbiana, $\mathrm{C}_{\mathrm{FL}}$ : carbono associado à fração leve; $\mathrm{C}_{\mathrm{FP}}$ : carbono associado à fração pesada (C-areia + C-silte + Cargila); EstC: estoque de CO; EstN: estoque de NT. Os dados de EstC e EstN foram obtidos das amostras coletadas na profundidade de $0-10 \mathrm{~cm}$; os dados dos demais atributos referem-se às amostras da profundidade de 0-5 $\mathrm{cm}$. Aumento ou redução em relação ao sistema MTN.

Quadro 6. Coeficientes de correlação de Pearson entre compartimentos do carbono orgânico e nitrogênio total de Latossolo Vermelho distroférrico típico do sul do Estado de Minas Gerais, na profundidade de 0-5 cm

\begin{tabular}{|c|c|c|c|c|c|c|}
\hline & $\mathrm{CO}$ & Cmic & $\mathbf{C}_{\mathrm{FL}}$ & C-areia & C-silte & C-argila \\
\hline Cmic & $0,94^{* *}$ & & & & & \\
\hline $\mathrm{C}_{\mathrm{FL}}$ & $0,84^{*}$ & $0,71^{\mathrm{ns}}$ & & & & \\
\hline $\mathrm{C}$-areia & $0,83^{*}$ & $0,64^{\mathrm{ns}}$ & $0,83^{*}$ & & & \\
\hline C-silte & $0,74^{\mathrm{ns}}$ & $0,85^{*}$ & $0,48^{\mathrm{ns}}$ & $0,45^{\mathrm{ns}}$ & & \\
\hline C-argila & $0,99^{* *}$ & $0,93^{* *}$ & $0,85^{*}$ & $0,78^{*}$ & $0,67^{\mathrm{ns}}$ & \\
\hline $\mathrm{NT}$ & $0,92^{* *}$ & $0,92^{* *}$ & $0,79^{*}$ & $0,59^{\mathrm{ns}}$ & $0,82^{*}$ & $0,93^{* *}$ \\
\hline
\end{tabular}

${ }^{*},{ }^{* *} \mathrm{e}^{\mathrm{ns}}$ : Significativos a 5 e $1 \%$ pelo teste de Tukey e não-significativo, respectivamente. 
correspondem, respectivamente, aos compartimentos ativo e lento da MOS, com tempo de ciclagem inferior ao $\mathrm{C}_{\mathrm{FP}}$, que representa o compartimento passivo da MOS (parte não viva e mais recalcitrante da MOS). Por essa razão, o $\mathrm{C}_{\text {mic }}$ e o $\mathrm{C}_{\mathrm{FL}}$ têm sido apontados por vários autores (D'Andréa et al., 2002; Roscoe \& Machado, 2002, Freixo et al., 2002; Matsuoka et al., 2003) como indicadores mais sensíveis para detectar modificações na MOS, antes mesmo que os teores de CO presentes em compartimentos mais estáveis da MOS sejam alterados de maneira significativa.

\section{CONCLUSÕES}

1. Os estoques de $\mathrm{CO}$ do solo na camada de $0-40 \mathrm{~cm}$ obedeceram à seguinte ordem decrescente: $\mathrm{EUC} \sim \mathrm{MTN} \sim \mathrm{PAS}>\mathrm{PIN} \sim \mathrm{MCM}>\mathrm{MPC}$. As áreas que armazenaram menos $\mathrm{N}$ no solo foram as cultivadas com milho.

2. Os teores de $\mathrm{C}$ da fração leve apresentaram reduções acentuadas (> $86 \%$ ) nos sistemas cultivados com milho, onde representaram de 1,1 a $2,3 \%$ do $\mathrm{CO}$ do solo.

3. O C-fração pesada (C-argila, C-silte e C-areia) representou mais de $90 \%$ do CO presente no solo.

4. Em relação à área sob mata, o cultivo do solo reduziu (28 a $68 \%$ ) os teores de $\mathrm{C}$ da biomassa microbiana, sendo as maiores perdas notadas nas áreas sob cultivo de milho.

\section{LITERATURA CITADA}

ANDERSON, T.H. \& DOMSCH, K.H. Ratios of microbial biomass carbon to total organic matter in arable soils. Soil Biol. Biochem., 21:471-479, 1989.

BATJES, N.H. Management options for reducing $\mathrm{CO}_{2}$ concentrations in the atmosphere by increasing carbon sequestration in the soil. The Netherlands, ISRIC. Wageningen, 1999. 114p.

BODDEY, R.M.; ALVES, B.J.R.; OLIVEIRA, O.C. \& URGUIGA, S. Potencial para acumulação e seqüestro de carbono em pastagens de Brachiaria. In: LIMA, M.A.; CABRAL, O.M.R. \& MIGUEZ, J.D.G., eds. Mudanças climáticas globais e a agropecuária brasileira. Jaguariúna, Embrapa Meio Ambiente, 2001. p.213-229.

BREMNER, J.M. Nitrogen total. In: SPARKS, D.L., ed. Methods of soil analysis. Madison, America Society of Agronomy, 1996. Part 3. p.1085-1121 (SSSA Book Series, 5).

CAMARGO, F.A.C.; GIANELLO, C.; TEDESCO, M.J. \& VIDOR, C. Nitrogênio orgânico do solo. In: SANTOS, G.A. \& CAMARGO, F.A.O., eds. Fundamentos da matéria orgânica do solo. Porto Alegre, Genesis, 1999. p.117-137.

CHRISTENSEN, B.T. Organic matter in soil: Structure, function and turnover. In: PLANT production. Tjele, 2000. p. 95. (DIAS Report, 30)
CHRISTENSEN, B.T. Physical fractionation of soil and organic matter in primary particle size and density separates. Adv. Soil Sci., 20:1-90, 1992.

COLLINS, H.P.; PAUL, E.A.; PAUSTIAN, K. \& ELLIOTT, E.T. Characterization of soil organic carbon relative to its stability and turnover. In: PAUL, E.A.; PAUSTIAN, K.; ELLIOTT, E.T. \& COLE, C.V., eds. Soil organic matter in temperate agroecossystems: Long-term experiments in North America. Boca Raton, CRC Press, 1997. p.51-72.

COMISSÃO DE FERTILIDADE DO SOLO DO ESTADO DE MINAS GERAIS - CFSEMG. Recomendações para o uso de corretivos e fertilizantes em Minas Gerais, $4^{a}$ aproximação. Lavras, Universidade Federal de Lavras, 1989. $176 \mathrm{p}$.

D'ANDRÉA, A.F.; SILVA, M.L.N.; CURI, N. \& GUILHERME, L.R.G. Estoques de carbono e nitrogênio e formas de nitrogênio mineral em um solo submetido a diferentes sistemas de manejo. Pesq. Agropec. Bras., 39:179-186, 2004 .

D’ANDRÉA, A.F.; SILVA, M.L.N.; CURI, N.; SIQUEIRA, J.O. \& CARNEIRO, M.A.C. Atributos biológicos indicadores da qualidade do solo em sistemas de manejo na região do cerrado no sul do estado de Goiás. R. Bras. Ci. Solo, 26:913923, 2002

DAY, P.R. Particle fractionation and particle-size analysis. In: BLACK, C.A., ed. Methods of soil analysis. Madison, American Society of Agronomy, 1965. Part.1. p.545-566.

ESTADOS UNIDOS. Department of Energy. Sequestration of carbon: State of the science. Washington, 1999. Não Paginado.

FEIGL, B.J.; SPARLING, G.P.; ROSS, D.J. \& CERRI, C.C. Soil microbial biomass in Amazonian soils: Evaluation of methods and estimates of pool sizes. Soil Biol. Biochem., $27: 1467-1472,1995$.

FERREIRA, D.F. Análises estatísticas por meio do Sisvar para Windows 4. 0. In: REUNIÃO ANUAL DA REGIÃO BRASILEIRA DA SOCIEDADE INTERNACIONAL DE BIOMETRIA, 45., São Carlos, 2000. Anais. São Carlos, Universidade Federal de São Carlos, 2000. p.255-258.

FONSECA, S.; BARROS, N.F.; NOVAIS, R.F.; LEAL, G.L.; LOURES, E.G. \& MOURA FILHO, V. Alterações em Latossolo sob eucalipto, mata natural e pastagem: IIpropriedades orgânicas e microbiológicas. R. Árvore, 17:289-302, 1993

FREIXO, A.A.; MACHADO, P.L.O.A.; GUIMARÃES, C.M.; SILVA, C.A. \& FADIGAS, F.S. Estoques de carbono e nitrogênio e distribuição de frações orgânicas de Latossolo do Cerrado sob diferentes sistemas de cultivo. R. Bras. Ci. Solo, 26:425-434, 2002.

GAVINELLI, E.; FELLER, C.; LARRÉ-LARROUY, M.C. \& BACYE, B. A routine method to study soil organic matter by particle-size fractionation: examples for tropical soils. Comm. Soil Sci. Plant Anal., 26:1749-1760, 1995.

GERALDES, A.P.A.; CERRI, C.C. \& FEIGL, B.J. Biomassa microbiana de solo sob pastagem na Amazônia. R. Bras. Ci. Solo, 19:55-60, 1995. 
GOLCHIN, A.; BALDOCK, J.A. \& OADES, J.M. A model linking organic matter decomposition, chemistry, and aggregate dynamics. In: LAL, R.; KIMBLE, J.M.; FOLLETT, R.F. \& STEWART, B.A., eds. Soil processes and the carbon cycle. Boca Raton, CRC Press, 1997. p.245-266. (Advances in Soil Sciences Series)

GOLCHIN, A.; OADES, J.M.; SKJEMSTAD, J.O. \& CLARKE, P. Structural and dynamic properties of soil organic matter as reflected by $13 \mathrm{C}$ natural abundance, pyrolisis mass spectrometry and solid-state 13C NMR spectroscopy in density fractions of an Oxisol under forest and pasture. Aust. J. Soil Res., 33:59-76, 1995.

GREGORICH, E.G. \& ELLERT, B.H. Light fraction and macroorganic matter in mineral soils. In: CARTER, M.R., ed. Soil sampling and methods of analysis. Boca Raton, Lewis, 1993. p.397-407.

GUGGENBERGER, G.; ZECH, W. \& THOMAS, R.J. Lignin and carbohydrate alteration in particle-size separates of an Oxisol under tropical pastures following native savanna. Soil Biol. Biochem., 27:1629-1638, 1995.

JENKINSON, D.S. \& LADD, J.N. Soil biochemistry. In: PAUL, E.A. \& LAAD, J.N., eds. Microbial biomass in soil: Measurement and turnover. New York, Dekker, 1981. p.415-471.

LAL, R. The potential of soils of the tropics to sequester carbon and mitigate the greenhouse effect. Adv. Agron., 74:155 192, 2002.

LAL, R. \& BRUCE, J.P. The potential do world cropland soils to sequester $\mathrm{C}$ and mitigate the greenhouse effect. Environ. Sci. Pollut., 2:177-185, 1999.

LEITE, L.F.C.; MENDONÇA. E.S.; NEVES, J.C.L.; MACHADO, P.L.O.A. \& GALVÃO, J.C.C. Estoques totais de carbono orgânico e seus compartimentos em Argissolo sob floresta e sob milho cultivado com adubação mineral e orgânica. R. Bras. Ci. Solo, 27:821-832, 2003.

LIMA, V.C.; LIMA, J.M.J.C.; CERRI, C.C. \& FRANZON, J.F. Efeito da substituição de campo natural por Pinus na dinâmica de carbono do solo. R. Setor Ci. Agric., 14:7-12, 1995 .

LUIZÃO, R.C.; CAMPISTA, D.; COSTA, E.S. Efeito da idade e do manejo das pastagem na Amazônia Central sobre a biomassa microbiana e suas atividades no solo. In: SIMPÓSIO BRASILEIRO DE MICROBIOLOGIA DO SOLO, 2., São Paulo, 1994. Anais. São Paulo, 1994. p.49.

LUTZOW, M. von; LEIFELD, J.; KAINZ, M.; KNABNERKOGEL, I. \& MUNCH, J.C. Indications for soil organic matter quality in soil under different management. Geoderma, 105:243-258, 2002.

MACHADO, P.L.O.A. Fracionamento físico do solo por densidade e granulometria para a quantificação de compartimentos da matéria orgânica do solo: um procedimento para a estimativa pormenorizada do seqüestro de carbono pelo solo. Rio de Janeiro, Embrapa Solos, 2002. 6p. (Comunicado Técnico, 9).

MADEIRA, M.A.V.; ANDREUX, P.P. \& PORTAL, J.M. Changes in soil organic matter characteristics due reforestation with Eucalyptus globules, in Portugal. Sci. Total Environ., 81/82:481-488, 1989.
MATSUOKA, M.; MENDES, I.C. \& LOUREIRO, M.F. Biomassa microbiana e atividade enzimática em solos sob vegetação nativa e sistemas agrícolas e perenes na região de Primavera do Leste (MT). R. Bras. Ci. Solo, 27:425433, 2003 .

MIELNICZUK, J.; BAYER, C.; VEZZANI, F.M.; LOVATO, T.; FERNANDES, F.F. \& DEBARBA, L. Manejo de solo e culturas e sua relação com os estoques de carbono e nitrogênio do solo. In: CURI, N.; MARQUES, J.J.; GUILHERME, L.R.G.; LIMA, J.M.; LOPES, A.S. \& ALVAREZ V., V.H. Tópicos em ciência do solo. Viçosa, MG, Sociedade Brasileira de Ciência do Solo, 2003. v.3. p.209-248.

MOREIRA, F.M. \& SIQUEIRA, J.O. Microbiologia e bioquímica do solo. Lavras, Universidade Federal de Lavras, 2002. 625 p.

OLIVEIRA FILHO, A.T.; SCOLFORO, J.R.S. \& MELLO, J.M. Composição florística e estrutura comunitária de uma remanescente de floresta semidecídua montada em Lavras, MG. R. Bras. Bot., 17:167-182, 1994.

PARFITT, R.L.; THENG, J.S.; WHITTON, J.S. \& SHEPHERD, T.G. Effects of clay minerals and land use on organic matter pools. Geoderma, 75:1-12, 1997.

PARTON, W.J.; SCHIMEL, D.S.; COLE, C.V. \& OJIMS, D.S. Analysis of factors controlling soil organic matter levels in great plains grasslands. Soil Sci. Soc. Am. J., 51:11731179, 1987.

PAUL, E.A. \& CLARK, F.E. Soil microbiology and biochemistry. San Diego, Academic Press, 1989. 272p.

POHLMAN, A.A. \& MCCOLL, J.G. Soluble organic from forest litter and their role in metal dissolution. Soil Sci. Soc. Am. J., 52:265-271, 1988.

POWLSON, D.S.; BROOKS, P.C. \& CHRISTENSEN, B.T. Measurement of soil microbial biomass provides an early indication of changer in total soil organic matter due to straw incorporation. Soil Biol. Biochem., 19:159-164, 1987.

ROSCOE, R. \& BUURMAN, P. Tillage effects on soil organic matter in density fractions of a Cerrado Oxisol. Soil Till. Res., 70:107-119, 2003.

ROSCOE, R. \& MACHADO, P.L.O.A. Fracionamento físico do solo em estudos da matéria orgânica. Rio de Janeiro, Embrapa Solos, 2002. 86p.

ROVIRA, P. \& VALLEJO, V.R. Labile and recalcitrant pools of carbon and nitrogen in organic matter decomposing at different depths in soil: An acid hydrolysis approach. Geoderma, 107:109-141, 2002.

SAUERBECK, D.R. $\mathrm{CO}_{2}$ emissions and $\mathrm{C}$ sequestration by agriculture: Perspectives and limitations. Nutr. Cycl. Agroecosyst., 60:253-266, 2001.

SCHOLES, M.C.; POWLSON, D. \& TIAN, G. Input control of organic matter dynamics. Geoderma, 79:25-47, 1997.

SILVA, C.A. \& MACHADO, P.L.O.A. Seqüestro e emissão de carbono em ecossistemas agrícolas: Estratégias para o aumento dos estoques de matéria orgânica em solos tropicais. Rio de Janeiro, Embrapa Solos, 2000. 23p. (Documentos, 19). 
SILVA, F.C. Manual de análises químicas de solos, plantas e fertilizantes. Brasília, Embrapa Comunicação para Transferência de Tecnologia, 1999. 370p.

SIQUEIRA, J.O.; NAIR, M.G.; HAMMERSCHMIDT, R. \& SAFIR, G.R. Significance of phenolic compounds in plantsoil-microbial systems. Crit. Rev. Plant Sci., 10:63-121, 1991.

SMITH, J.L. \& PAUL, E.A. The significance of soil microbial biomass estimations. In: BOLLAG, J.M. \& STOTSKY, G., eds. Soil biochemistry. New York, Marcel Dekker, 1990. p.357-398.

SOHI, S.P.; MAHIEU, N.; ARAH, J.R.M.; POWLSON, D.S.; MADARI, B. \& GAUNT, J.L. A procedure for isolating soil organic matter fractions suitable for modeling. Soil Sci. Soc. Am. J., 65:1121-1128, 2001.

SOUZA, W.J.O. \& MELO, W.J. Matéria orgânica de um Latossolo submetido a diferentes sistemas de produção de milho. R. Bras. Ci. Solo, 27:1113-1122, 2003.

STEVENSON, F.J. Humus chemistry: Genesis, composition, reactions. 2.ed. New York, John Wiley \& Sons, 1994. 496p.
TEIXEIRA, L.B. \& BASTOS, J.B. Matéria orgânica nos ecossistemas de floresta primária e pastagem na Amazônia central. Belém, Embrapa-CPATU, 1989. 26p. (Boletim de Pesquisa, 99).

TURNER, J. \& LAMBERT, M. Changes in organic carbon in forest plantation soils in eastern Australia. For. Ecol. Manag., 133:231-247, 2000.

VANCE, E.D.; BROOKES, P.C. \& JENKINSON, D.S. An extraction method for measuring soil microbial biomass C. Soil Biol. Biochem., 19:703-707, 1987.

YEOMANS, J.C. \& BREMNER, J.M. A rapid and precise method for routine determination of organic carbon in soil. Comm. Soil Sci. Plant Anal., 19:1467-1476, 1988.

ZINN, Y.L.; DIMAS, V.S. \& SILVA, J.E. Soil organic carbon as affected by afforestation with Eucalyptus and Pinus in the Cerrado region of Brazil. For. Ecol. Manag., 166:285294, 2002.

ZINN, Y.L.; LAL, R. \& RESCK, D.V.S. Changes in soil organic carbon stocks under agriculture in Brazil. Soil Till. Res., 84:28-40, 2005. 